\title{
The Impact of E-Learning on the Use of Campus Instructional Space
}

\author{
Tatiana Bourlova and Mark Bullen \\ The University of British Columbia, Distance Education \& Technology, \\ Centre for Managing and Planning Learning Environments, \\ 2329 Main Mall \#1170, Vancouver, B.C. V6R 1Z4, Canada \\ tatiana.bourlova@ubc.ca \\ mark.bullen@ubc.ca \\ http: / / www.maple.ubc.ca/
}

\begin{abstract}
The use of e-leaning is growing in universities and colleges across North America but these institutions do not fully understand how and in what form it can contribute to their missions, what the indicators of the successful implementation of e-learning would be, and how to assess the changes caused by e-learning. The study approaches e-learning from the institutional perspective, outlining the effects of e-learning on the use of the instructional space on campus.
\end{abstract}

\section{Introduction}

The use of e-learning is growing in universities and colleges across North America but these institutions do not fully understand how and in what form it can contribute to their missions, what the indicators of the successful implementation of e-learning would be, and how to assess the changes caused by e-learning. The following study approaches e-learning from the institutional perspective, outlining the effects of elearning on the use of the instructional space on campus. E-learning is defined as the use of the Internet and Internet-based communication technologies to deliver education and training.

Many Canadian universities are unable to meet the increasing demand for higher education because of a lack of adequate instructional facilities. Often, highly qualified applicants are denied access because of this space shortage (Johnston, 2002). Another factor contributing to the access problem is growing tuition fees. For instance, in the province of British Columbia university tuition fees increased by approximately $50 \%$ between 2001 and 2003 and more increases are expected (Dumaresq, et al., 2004). The growing cost of education leads many students to seek employment to meet financial needs (Survey of First-Year University Students, 2001, 2004; Graduating Students Survey, 2000, 2004). While the number of on-campus students who are employed grows, they are also spending more time on education than they did just a decade ago (PCEIP, 2003). At the same time student enrolment in higher education institutions is growing. It has been estimated that by 2011, universities in Canada will need collectively to respond to a projected 20-30\% increase in demand (AUCC, 2003). 
Universities are employing a variety of strategies to deal with this increased demand. E-learning has been suggested as one strategy. E-learning has its roots in distance education which has been used by higher education institutions for over 60 years to provide flexible access to learners who are unable to come to campus. However, a number of studies suggest most students enrolled in distance education courses are now full-time students on campus (Zemsky, Massy, 2004; Hartman, Dzuiban, Moskal; 2004). In addition to e-learning as distance education, we see an increasing use of what is called mixed-mode (Bates, 2001, 2003) or blended forms (Hartman, et al. 1999, 2004) that involve reduced face-to-face contact supplemented with Internetdelivered instruction and interaction. For the next five years the University of British Columbia, for instance, plans to increase the use of e-learning to $12.5 \%$ of all undergraduate full time equivalent students (FTEs) (ACCULT, 2000). Other universities and colleges may have similar plans to make more use of mixed-mode e-learning. But we do not fully understand how e-learning can be used to deal with the access problems beyond providing fully online distance education courses. For most students this is not a preferred option as the on-campus experience, at least at the undergraduate level, is still highly valued by both students and academics (Bates, 2001, 2003). Using e-learning in mixed-mode forms, in which some face-to-face instruction is replaced by Internet-based activity, is a preferred option (Massy, Zemsky, 2004). But what impact will this use of e-learning have on the use of campus classroom space? Can elearning be used to meet the needs of working students in a flexible schedule, and to ease the pressure on the university campus facilities caused by the growing demand?

In 2002, the Centre for Managing and Planning E-Learning (MAPLE) at the University of British Columbia began to investigate the impact of e-learning on the campus. This research has resulted in the creation of a basic model for assessing the changes to the campus instructional space occupancy caused by the hypothetical implementation of e-learning in its fully online form for a certain number of courses on campus.

\section{Modes of E-Learning and Implementation Scenarios}

Our study examined several aspects of a university system: the size of the on-campus population, courses and programs (in terms of the modes of instruction, overall number of the courses and instruction time), and instructional space occupancy. The purpose of the study was to find a way of accurately predicting the effects of e-learning on campus space use so that university administrators might be better able to manage the pressure of increasing demand and stagnant or declining funding.

In order to estimate the cumulative effect of e-learning on campus instructional space, clear definitions for the different modes of e-learning are needed. Most researchers and practitioners distinguish three basic modes of e-learning (Hartman \& Dziuban, 2004):

- In web-enhanced mode involves the enhancement of face-to-face courses through the pedagogically significant use of the Web using a course management system, but seat time is not reduced.

- Mixed mode (blended) instruction involves a fundamental redesign of instruction in which some face-to-face teaching is replaced with online instruction and 
"the socialization opportunities of the classroom are combined with the technologically-enhanced learning possibilities of the online environment" (p.3).

- Wholly online instruction implies online instruction with no face-to-face instructional contact. This mode of instruction, used for the students on campus, has a potential to reduce the demand for on-campus facilities, such as classrooms and laboratories.

It has been suggested that mixed-mode implementations of e-learning hold the most promise for making more efficient use of classroom space while maintaining the quality of instruction (Bates, 2001, 2003; Hartman, Dziuban, Moskal, 1999, 2004). However, these definitions do not refer directly to any quantitative indicators, which could be used for the assessment of impact. How much e-learning must be implemented at a university for it to make a meaningful difference to instructional space occupancy? What formats of e-learning have the most impact?

There are several interconnected steps involved in estimating the impact of elearning on campus: establishing the measurement units for certain elements of the campus system, defining the historical trends in their functioning, defining e-learning in terms of the chosen elements, and finally, discovering and describing the functional dependencies between the variables in question.

We constructed and tested several indicators. If the statistics on the nature of courses (modes of instruction) is available, it is easy to define the extent of e-learning in an institution. Unfortunately, these statistics often do not exist, and classroom use databases often do not indicate how many courses on campus use e-learning, and to what extent. Another uncertainty in measuring the amount of e-learning in an institution is that it can vary for every mixed mode (blended) course. For example, if a traditional classroom-based course requires student attendance in a class twice a week, then using a mixed-mode e-learning approach could require students to be on-campus just once a week, once every two weeks or once a month. Thus, the amount of time that students are required to spend on campus in mixed-mode implementations can vary considerably. Researchers at the Rochester Institute of Technology define blended courses through the course activities or the time-on-task. If approximately $25 \%$ to $50 \%$ of the face-to-face classroom activities are replaced by instructor-guided online learning activities, then the course is blended (Blended Learning Project, 2004). Indeed, the proportions of in-class and online course activities can vary considerably. In our research, to identify the proportion of e-learning in a mixed mode course we use "class-hour equivalent" as a unified measure. By class-hour equivalent we mean the number of hours that an online course, or online portions of a blended course, requires for instruction. Another unit of measure is the number of students enrolled in the courses. The amount of e-learning can be estimated through the proportion of registrations in the traditional face-to-face courses to the number of registrants in the courses with e-learning. One more unit of measure that can be used to estimate the overall extent of e-learning in a university is a course. We can define the amount of e-learning in a higher education institution via the proportion of traditional campus-based courses to the courses in e-learning formats. With these indicators the base level of e-learning on campus can be defined. The overall impact then can be estimated as the difference between the projection of the current trends in classroom space occupancy, and the changes, that are likely to result from the introduction of a certain amount of e-learning. We developed three e-learning implementation scenar- 
ios to find out in what conditions these types and amounts of e-learning make a difference for the instructional space occupancy.

Scenario \#1: One classroom-based course is transformed into one online course. This example illustrates the case when a course was initially taught face-to-face, and later transformed to fully online mode (i.e., replacing classes on campus). For instance, if an additional section (or several sections) of the course are offered online, then the impact of this implementation (the difference) can be calculated using the following variables: the number of registrations in the course (which can grow exponentially after the implementation of e-learning), the number of classrooms (the course would not need additional classrooms), and the hours when the classrooms were occupied (the periods of time when the course required scheduling classrooms, which would also decrease).

Introducing additional online sections, or replacing existing classroom-based courses, could result in an increase in enrollments without a corresponding increase in the use of instructional space on campus. In a different case, if an online course was initially created for online delivery (as a distance course), it produces no effect on the campus space occupancy. However it is still possible to estimate the weight of this course in the overall amount of e-learning at the institution using the class-hour equivalent variable.

Scenario \#2: One classroom-based course is transformed into two sections of mixed mode format. This scenario produces a different impact. If half of the instructional time is used for face-to-face teaching and another half goes online, the number of registrations in the course could double, without an increase in instructional space occupancy. Big lecture courses can be split in this way in order to reduce class size and to increase the amount of teacher-student interaction.

The impact of mixed mode e-learning also can be estimated via the number of registrations. So, we can define how many new registrants can take the course due to the scheduling of additional sections. The class-hour equivalent in this case would represent how many hours of instruction would not require scheduling the classrooms oncampus. However, the impact on the instructional space occupancy will be zero in this case, because the same classroom would be occupied for the same hours, as it was before the introduction of e-learning. But more students could use it due to e-learning.

Scenario \#3: One classroom-based course is transformed into one mixed mode course. This scenario represents the implementation of a mixed mode course format that could result in students spending fewer hours on campus. If a classroom-based course has been transformed into the mixed mode course, with half of the course time intended for classroom activities and another half - for online instruction, then the number of registrants could probably stay the same, the same classroom would be required for the course, and only the schedule time would be different.

The effect in this case could be that - with the same number of registrants, the classrooms (or laboratories) are occupied less and can be scheduled for some other classes. In this scenario, the resulting impacts can be measured via the class-hour equivalent, indicating the proportion of online and in-classroom course activities and the corresponding changes in instruction space occupancy on campus.

These basic assumptions were used for creating the model for the evaluation of the impact of e-learning at the University of British Columbia. To determine how much 
of these types of e-learning UBC currently has, and its impact on campus facilities, a snapshot of the campus conditions was made. It included the historical change in student enrolment, the number and types of courses, and on-campus instructional space occupancy.

\section{UBC Case Study}

Over the last ten years student enrolment at UBC has outgrown the increase in instructional space and the increase in instructors. The number of students on campus grew by $3.2 \%$ per year while the amount of space increased by only $0.2 \%$ and the number of instructors increased by $2.3 \%$ (PAIR, 2002; 2003).This disproportion could be partly responsible for the lack of university seats available to students. Access is a pressing issue for the universities as demand continues to increase. E-learning is one way of addressing the lack of physical space, but universities still need to attract and retain high quality faculty, capable and willing to use e-learning.

Currently only about $1 \%$ of all UBC courses are offered in mixed mode format, and $2 \%$ are offered online as distance courses (OECD, 2003). It is quite evident, that these small amounts of e-learning do not have much impact on the UBC instructional space occupancy. However, it still useful to know if e-learning were implemented more widely, what impact it would have on instructional space. The purpose of this study was to develop a method for measuring that impact.

We used data from the period 1997-2003 provided by UBC Classroom Services. Work time and academic terms were defined as follows:

- Academic terms: the first term runs from the 4th to 16th weeks, and the second term runs from the 21 st to 34 th weeks of academic year.

- Work-time: this is the time interval during which the classrooms are available for teaching. Work-time intervals usually vary from 14 hours down to 6 peak hours per day.

The number of classes outside of these terms' periods and beyond the peak hours were insignificant. We determined time intervals and the number of classrooms, during which these were occupied for instruction in a specified year/term. An average amount of time, during which the classrooms are occupied (Occupancy Time) is measured in hours and in the percentage of work-time. The number of classrooms occupied during a term (Average Number of Occupied Classrooms) is measured as a number of classrooms in use, regardless to their size, and as a percentage of the occupied rooms to the whole classroom pool.

The analysis of the UBC course schedules, made for the five year period from $1998 / 99$ to $2002 / 03$, reveals that on average $79.6 \%$ of the, classrooms are occupied at peak hours (415 out of 497). Of the six peak hours, on average the classroom space is occupied for $58.1 \%$ of that time or for three hours and 29 minutes. In terms of the standards for the use of the university classroom space, these figures represent a very good rate of utilization (Fink, 2002; 2003). But we also know that there is an access problem. How can we make the use of instructional space more efficient to address the problem of access? 
We supplemented the statistical analysis with mathematical modeling, creating a descriptive image of the chosen functions of the campus system in order to predict and estimate how the system would be affected by e-learning implemented on campus. We developed a computer tool for a "what if" scenario, to find out whether there could be any proof for the improved use of instructional space on campus. The UBC historical data on the number of occupied classrooms and course schedule time were used for modeling the classroom occupancy for an hypothetical case in which four big classroom-based lecture courses are transformed into an e-learning format (testing the first scenario). The prognostic evaluation of the impact was based on a linear extrapolation of the current trend in the classroom space occupancy and the extrapolation of the hypothetical trend with the changes that occur with the suggested amount of e-learning.

The pie chart (Figure 1) shows the resulting on-campus/online course ratio for all UBC courses. The graphs on this figure show the difference between the current trend in classroom occupancy (solid line) and the hypothetical trend with the established amount of e-learning (dotted line). If this particular scenario were implemented for the selected courses on campus, then the result would be $11.27 \%$ difference in the classroom occupancy time; and $14.9 \%$ difference - in the number of occupied classrooms comparing to the previous occupancy of learning spaces. This means that out of 415 classrooms (that are occupied during peak hours on campus) 74 of these can be made available for the course instruction within the time periods during which these classrooms previously were in use (Bourlova; 2004). The parameters of this elearning scenario can be changed and adjusted to the needs of a particular institution. This provides university administrators with more flexibility in managing instructional space and student enrolment. This achieved flexibility can be used for class scheduling in many different ways: accommodating more students in the most popular courses (offering additional course sections at the available classrooms), splitting big lecture classes into a small group teaching format, and also offering more diverse schedule options for the students and instructors on campus. The net effect of this scenario is that fewer classrooms are occupied for less time.

It is important to note that the outlined functional dependences are closely related to other campus conditions. The implementation of e-learning on-campus also requires the university to have enough professors to teach and the IT support staff to provide assistance to instructors and learners in the online environment. If these conditions are not met, then the advantages in improved use of instructional space become dubious. The positive impacts on the use of classroom space caused by elearning would not be realized, if the university instructors are not motivated to teach using e-learning, or if adequate course design and technical support is not provided. Faculty support is critical to the successful implementation of e-learning (Hanrahan, Ryan, Duncan; 2001).

We have only tested the scenario, in which classroom-based courses are transformed into fully online format. The model shows it is possible to calculate and predict the potential impact of e-learning on campus before any decision on its implementation is made. With this model we also tested the applicability of the constructed variables to this kind of analysis. The model will be further developed to handle the mixed-mode scenarios of e-learning for on-campus use.

It is also important to emphasize that using e-learning to alleviate classroom space shortages should not be the primary reason for universities to adopt it. Research and 
practice suggests that e-learning, particularly in its mixed mode and distance education modes, can have a positive impact on the learning experience (Dzuiban, Hartam \& Moskal, 2004; Bates, 2000). This study helps inform one aspect of university decision-making related to e-learning; decisions about whether and how to implement elearning should be driven by its broader educational and social impact. Further studies are needed to clarify how and in what form e-learning can contribute to the instruction practices and to students educational experiences.

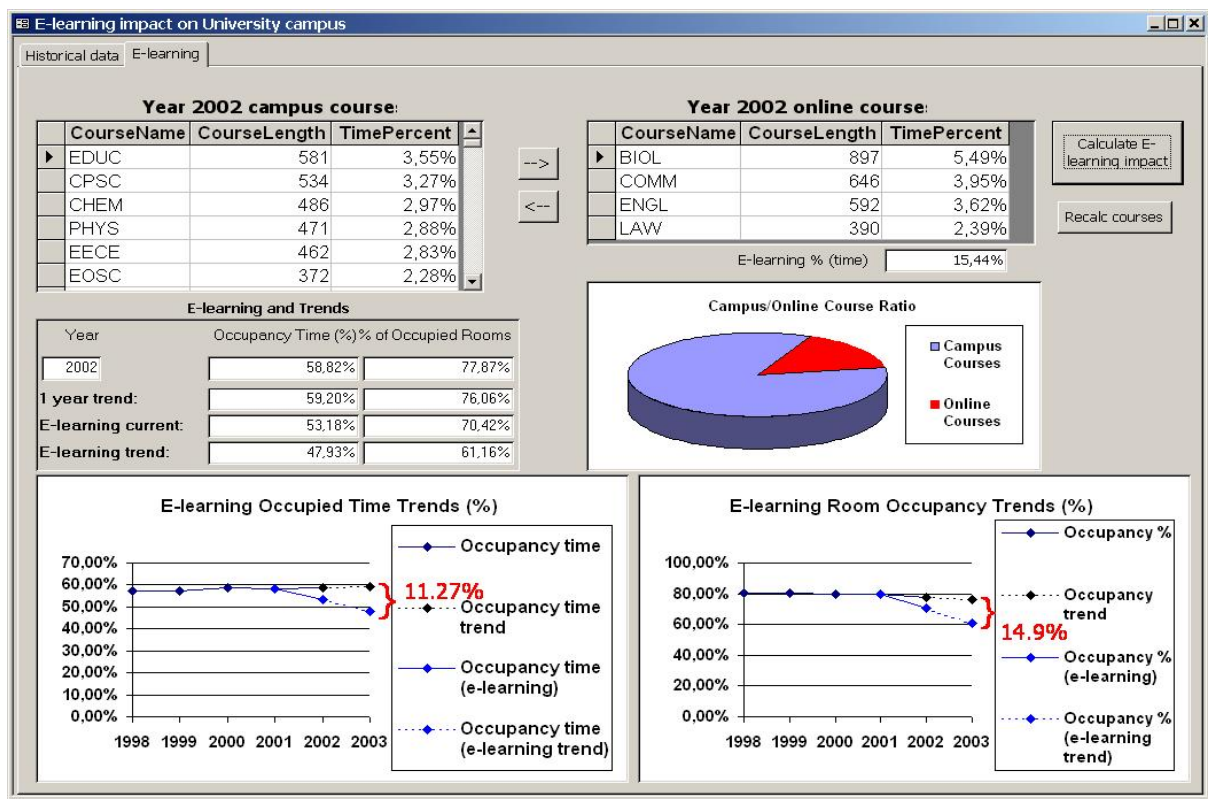

Fig. 1. Modeling the Impact of E-learning on the Campus Instructional Space Occupancy

\section{Summary}

The results of this study provide only a first step in the development of a full body of standard procedures for the evaluation of the diverse effects of e-learning when it is implemented in higher education.

Our analysis of the impact of e-learning on the university campus revealed that:

- The introduction of mixed-mode e-learning and fully online sections for nondistance courses leads to the reduction of classroom space occupancy on campus.

- E-learning will only have an impact on campus facilities if the course in question was initially taught face-to-face on campus and later transformed to fully online or mixed mode. The anticipated effect of the introduction of online sections for an existing classroom-based course is a potential increase in student enrolment without the increased use of instructional space on campus. 
- If an online course was initially created for distance education, then its implementation has no effect on the campus space occupancy. In other words, even extensive use of e-learning at a higher education institution could have no effect on the campus instructional space occupancy if the e-learning courses are developed and delivered as distance courses and they do not replace existing face-to-face courses. The "weight" of the distance courses in the overall amount of e-learning at a university can be estimated using the "class-hours equivalent" variable.

- E-learning implemented for on-campus use provides flexibility in scheduling courses and improves the use of limited resources, such as classrooms and laboratories.

Many institutions do not collect the type of data needed for this type of study, as no standard indicators and procedures are yet established for the analysis of the impacts of e-learning on higher education institutions. However, this information can be crucial for successful planning based on the evaluation of the prior conditions and modeling the expected effects of the use of e-learning on-campus. Regular monitoring of the parameters of campus functioning that we outlined can help to better understand and predict how to manage the changes, realize the major benefits of e-learning and at the same time identify and prevent undesirable side effects.

\section{References}

1. ACCULT - Academic Committee for the Creative Use of Learning Technologies (2000). The Creative Use of Learning Technologies. UBC. Retrieved March, 2005, www.maple.ubc.ca/research/accult/index_accult.html

2. AUCC Publications (2003). Trends in Higher Education. Retrieved March, 2005, www.aucc.ca/publications/auccpubs/research/trends/summary_e.html

3. Bates, A. W. (2000). Managing Technological Change: Strategies for College and University Leaders. Jossey-Bass Publishers: San Francisco.

4. Bates, A. W. (2001). National Strategies for E-learning in Post-Secondary Education and Training. Paris: UNESCO: International Institute for Education and Planning.

5. Blended Learning Project Final Report for the Academic Year 2003-2004 (2004). Online Learning Department. Rochester Institute of Technology.

6. Bourlova, T. (2004). The Impact of E-learning on a University Campus. Final project report. Retrieved March, 2005, www.maple.ubc.ca/researc/impact_project.html

7. CAUT / ACPPU (2003). Almanac of Post-Secondary Education in Canada.

8. Dumaresq, Ch., Lambert-Maberly, A., Sudmant, W. (2004). University Accessibility and Affordability. PAIR. UBC. Retrieved July, 2004, www.pair.ubc.ca/studies/tuitafford0304.htm\#_Toc64186002

9. Fink, I. (2002). Classroom Use and Utilization, Faculty Manager, FAIA, May/June 2002.

10. Fink, I. (2003). Benchmarking. A new approach to space planning. Connecting the Dots... the Essence of Planning. The Best of Planning for Higher Education 1997-2003. Ed. by Rod Rose. The Society for College and University Planning.

11. Graduating Students Survey. (2000). (2004). The Master Report for the Canadian Undergraduate Survey UBC. Retrieved May, 2004 www.pair.ubc.ca/studies/cusc2003.htm 
12. Hanrahan, M., Ryan, M., Duncan, M. (2001). The professional engagement model of academic induction into on-line teaching. International Journal for Academic Development. Vol. 6, No. 2, pp. 130-142.

13. Hartman J., Dzuiban, Ch., Moskal, P. (2004). Blended Learning. EDUCAUSE Centre for Applied Research. Research Bulletin, vol. 2004, Issue 7, March 30, 2004

14. Hartman, J., Dziuban, Ch., Moskal, P. (1999). Faculty Satisfaction in ALNs: A Dependent of Independent Variable? Sloan Summer ALN Workshops. Illinois, August 16-18, 1999.

15. Johnston, A. D. (2002). The University Crunch. MakLean's, November 18. Retrieved May, 2003, http://www.macleans.ca/xta-doc2/2002/11/18/Universities2002/75463.shtml

16. OECD (Organization for economic co-operation and development). (2004). E-learning case studies in post-secondary education \& training. UBC case study. Centre for educational Research and Innovation.

17. PAIR (2004). Planning and Institutional Research. The University of British Columbia Fact Book. Retrieved February, 2004, www.pair.ubc.ca/studies/factbook.htm

18. Report of the Pan-Canadian Education Indicators Program (PCEIP). Education Indicators in Canada. 2003. Retrieved December, 2004, www. cesc.ca ; www. statcan.ca

19. Survey of First-Year University Students (2001); (2004). Canadian Undergraduate Survey Consortium (CUSC) PAIR. UBC. Retrieved November, 2003; November, 2004, www.pair.ubc.ca

20. Zemsky, R., Massy, F. (2004). Thwarted Innovation. What Happened to e-learning and Why. A final report for the Weatherstation Project of the Learning Alliance at the University of Pennsylvania in cooperation with the Thomson Corporation. Retrieved May, 2004, www.thelearningalliance.info/Docs/Jun2004/ThwartedInnovation.pdf 